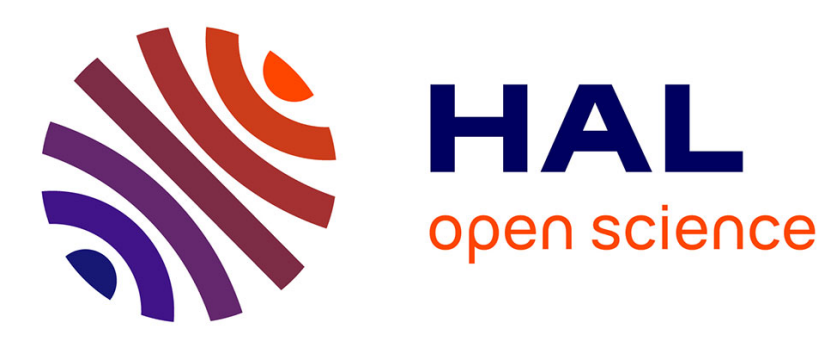

\title{
A new vibration reduction control strategy of switched reluctance machine
}

Man Zhang, Imen Bahri, Xavier Mininger, Cristina Vlad

\section{To cite this version:}

Man Zhang, Imen Bahri, Xavier Mininger, Cristina Vlad. A new vibration reduction control strategy of switched reluctance machine. Electric Machines and Drives Conference (IEMDC), 2017 IEEE International, May 2017, Miami, United States. 10.1109/iemdc.2017.8002114 . hal-01677842

\section{HAL Id: hal-01677842 \\ https://hal.science/hal-01677842}

Submitted on 16 Mar 2020

HAL is a multi-disciplinary open access archive for the deposit and dissemination of scientific research documents, whether they are published or not. The documents may come from teaching and research institutions in France or abroad, or from public or private research centers.
L'archive ouverte pluridisciplinaire HAL, est destinée au dépôt et à la diffusion de documents scientifiques de niveau recherche, publiés ou non, émanant des établissements d'enseignement et de recherche français ou étrangers, des laboratoires publics ou privés. 


\title{
A New Vibration Reduction Control Strategy of Switched Reluctance Machine
}

\author{
Man Zhang ${ }^{1}$, Imen Bahri ${ }^{1}$, Xavier Mininger ${ }^{1}$, Cristina Vlad $^{2}$ \\ ${ }^{1}$ Group of electrical engineering Paris (GeePs, UMR CNRS 8507); Gif-Sur-Yvette, France, name@geeps.centralesupelec.fr \\ ${ }^{2}$ Laboratoire des Signaux et Systèmes ( L2S, UMR CNRS 8506); Automatic Control Department, CentraleSupélec, Gif-Sur- \\ Yvette, France, cristina.vlad@centralesupelec.fr
}

\begin{abstract}
This paper proposes a control strategy capable of reducing the vibration while keeping a low torque ripple for a switched reluctance machine (SRM). The aim is to minimize the variation of the radial force and to optimize the torque control parameters. At first, the torque ripple reduction method is introduced, for which an off-line optimization of control parameters is adopted. Then, the vibration reduction is achieved by Direct Force Control (DFC), whose purpose is to reduce the variation of the sum of radial forces. However, in order to cope with the drawback of DFC that amplifies the torque ripple, a reference current adapter is proposed based on the limitation of torque and radial force variations. The reference current adapter produces an auto-tuning reference current that achieves a tradeoff between torque ripple and vibration. Finally, simulation results are presented to validate the effectiveness of the proposed control method under different operating points.
\end{abstract}

Keywords-direct force control; radial force; switched reluctance machine (SRM); vibration reduction

\section{INTRODUCTION}

The inherent advantages such as high robustness, low cost and high start torque have made switched reluctance machine (SRM) a strong candidate for electric vehicle applications. However, the doubly salient structure and highly non-linear magnetic field lead to serious vibration and noise problems, which have constrained deeply the application of SRM. The main cause of vibration and acoustic noise is considered to be the electromagnetic force between the stator and rotor poles [1]. In the literature, different approaches are proposed to solve this problem, which can be mainly divided into two categories: geometry optimization [2]-[4] from the aspect of mechanical / structural improvement and (semi-active/active) control strategies.

Among the control approaches, several strategies have been considered such as current shape optimization based on artificial neural networks [5], two-stage [6] or three-stage commutation methods [7] able to reduce the vibration at the dominant natural frequency or control methods based on a limited change rate of current during the turn-off [8]-[11]. An alternative method for vibration reduction is the semiactive/active control based on piezoelectric (PZT) actuators

This work is sponsored by CSC.
[12]-[15], where the number and the placement of actuators is optimized by genetic algorithms in order to reduce vibration.

In addition, several studies have been proposed to control the radial force directly. Moreover, researches in [16]-[18] point out that the variation of the radial force has a large impact on the vibration performance, which inspired the development of control methods aiming to obtain a smooth radial force. In [16], this objective is achieved by adopting the direct instantaneous force control (DIFC), along with a predictive controller used to compute the duty ratio of the PWM (PulseWidth Modulation). Moreover, the average toque control method is applied to ensure the required mean torque. In [17] [18], the variation of the sum of radial forces has been minimized using a current profile control method; however, the methods are only suitable for three-phase SRM.

In this paper, a novel control method is proposed to reduce the vibration of a SRM by handling the torque ripple at the same time. The structure of the paper is the following: the principle of the proposed control strategy is introduced in Section II and it consists of four parts: i) the torque ripple minimization control; ii) the direct radial force control, used to obtain a smooth overall radial force in order to improve the vibratory behavior; iii) the torque and radial force coupling, which aims to acquire the relationship between the equivalent torque and radial force; iv) the reference current adaptor, used to provide an adaptive reference current to balance the gap between torque ripple minimization and vibration reduction. In Section III, simulation results are provided using a $8 / 6$ poles SRM.

\section{Principle of Control Strategy}

\section{A. Torque Ripple Minimization Control}

The main control strategy for a $8 / 6$ poles SRM is the torque ripple minimization control (TMC), which is based on optimized control parameters: reference current $I_{r e f} *$, turn on angle $\psi$ and conduction angle $\theta_{p}$, whose definitions are presented in Fig. 1. This control strategy combines the PWMbased current-loop PI control with the switching angle signal as shown in Fig. 2. A look-up table stores the optimized control parameters, for which a minimum torque ripple is obtained for different operating points [19]. Thus, using the reference torque and actual rotor speed as inputs, the control parameters 

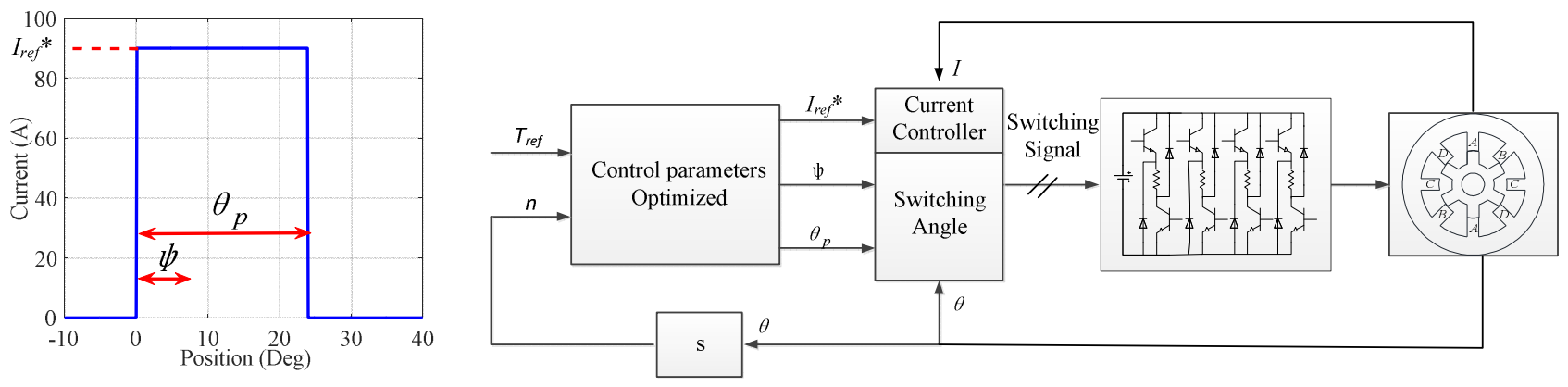

Fig. 1. Definition of control parameters.

Fig. 2. Structure of optimal torque control.

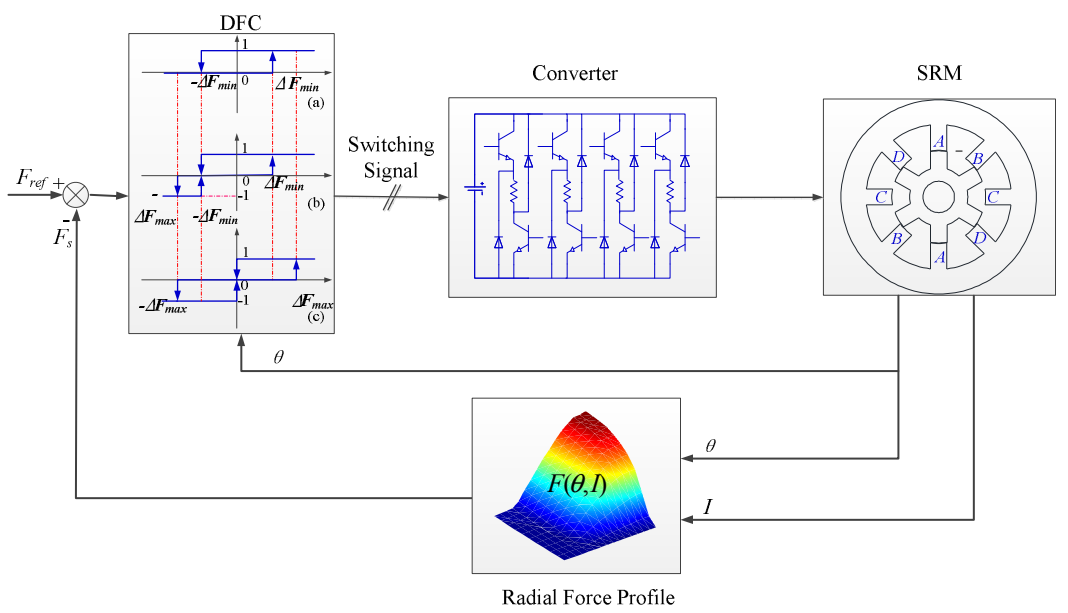

Fig. 3. Control scheme of DFC strategy.

$I_{r e f}^{*}, \psi$ and $\theta_{p}$ are constantly updated. Then, the error between the reference current $I_{r e f} *$ and the phase current $I$ is used by the PWM-based current control to compute a variable duty ratio such that the phase current tracks the reference value

\section{B. . Direct Force Control}

The direct force control (DFC) is a method based on direct instantaneous torque control [20], whose aim is to obtain a smooth overall radial force by controlling the converter switches so that the sum of radial forces generated in the stator phases can reach a desired value $F_{r e f}$. The control scheme of the SRM based on DFC is illustrated in Fig. 3.

The switching signals of the power converter are generated by the DFC block in order to reduce $\Delta F$, defined as the difference between the desired radial force $F_{\text {ref }}$ and the actual sum of the radial forces $F_{S}$ of each phase. Therefore, the direct force controller computes digital control signals that are further applied to the converter of the SRM. In this study, a traditional asymmetric half-bridge converter is adopted for the four-phase 8/6 SRM. Based on the states of two controllable switches and two diodes, each phase of the converter has three different operating modes in which it can provide positive, zero or negative terminal voltage to a SRM phase winding. Fig. 4 represents only one phase of the four-phase asymmetric halfbridge converter and its operating modes, where $U$ is the power supply voltage, and TABLE I. gives the operating modes of this converter.

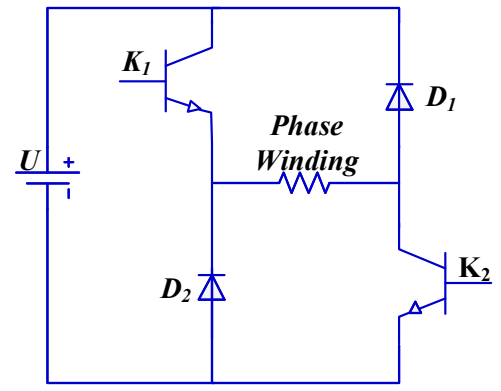

Fig. 4. One phase of the asymmetric half-bridge converte.

TABLE I. OPERATING MODES OF CONVERTER

\begin{tabular}{|l|c|c|c|}
\hline \multicolumn{1}{|c|}{ Operating mode } & $\boldsymbol{K}_{\mathbf{1}}$ & $\boldsymbol{K}_{\mathbf{2}}$ & $\begin{array}{c}\text { Applied phase } \\
\text { voltage }\end{array}$ \\
\hline $\begin{array}{l}S=1 \\
\text { (magnetized phase) }\end{array}$ & on & on & $U$ \\
\hline $\begin{array}{l}S=0 \\
\text { (freewheeling phase) }\end{array}$ & on/off & offlon & 0 \\
\hline $\begin{array}{l}S=-1 \\
\text { (demagnetized phase) }\end{array}$ & off & off & $-U$ \\
\hline
\end{tabular}

The DFC consists of double-band hysteresis-controllers that compute the switching signals for each phase of the machine. The advantage of using a double-band hysteresis control is a higher bandwidth which leads to a smoother total radial force and a lower switching frequency. The control process is divided into two control modes as shown in Fig. 5 
and the switching rules of the hysteresis-controller are depicted in Fig. 6. The outer and inner hysteresis bands are defined within the intervals $\left[-\Delta F_{\max }, \Delta F_{\max }\right]$ and $\left[-\Delta F_{\min }\right.$, $\left.\Delta F_{\min }\right]$. Taking phases $\mathrm{A}, \mathrm{B}$ and $\mathrm{D}$ for example, the first control mode is defined by two adjacent phases excited at the same time (periods I and III in Fig. 5). In this case, the switching states $S$ of the outgoing phase (phase D, period I or phase A, period III) and the incoming phase (phase A, period I or phase $\mathrm{B}$, period III) follow the rules in Fig. 6 (c) and Fig. 6 (a), respectively. The second control mode is described as a mode where a single phase is exited (phase A, period II) following the rules in Fig. 6 (b). When the second mode is active, the total radial force $F_{s}$ is adjusted by controlling only the excited phase, whereas during the first mode, the DFC is carried out by regulating both of the excited phases.

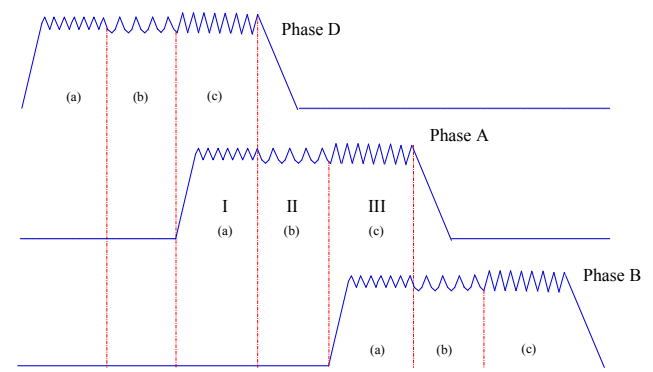

Fig. 5. Region division and control modes of the DFC.

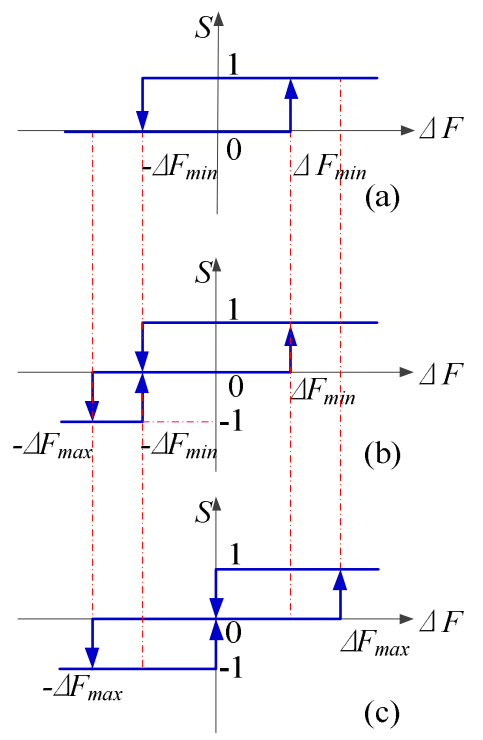

Fig. 6. Diagram of double-band hysteresis controllers.

Considering that the first control mode (period I and III) is active, when the control input $\Delta F$ is smaller than the lower bound $-\Delta F_{\max }$ of the outer hysteresis band, phase $\mathrm{D}$ is demagnetized $(S=-1)$ and phase A keeps freewheeling $(S=0)$. As a result, $\Delta F$ increases up to zero, which triggers phase $\mathrm{D}$ to switch to freewheeling. While $\Delta F$ keeps increasing, the switches of phase A turns on when $\Delta F$ reaches the upper bound $\Delta F_{\min }$ of the inner band, and phase $\mathrm{D}$ is magnetized once $\Delta F$ exceeds the upper limitation $\Delta F_{\max }$. With the excitation of both phase $\mathrm{A}$ and phase $\mathrm{D}, \Delta F$ starts to decrease. Thus, when $\Delta F=$ 0 , phase D switches into freewheeling and so is phase A when
$\Delta F \leq-\Delta F_{\min }$. If the sum of radial forces keeps increasing until $\Delta F \leq-\Delta F_{\max }$, phase $\mathrm{D}$ is demagnetized. With these commands above, the variation of the sum radial force can be reduced during the commutation period I and III.

During the second control mode (period II), only phase A is excited, phase D has been turned off. Supposing that the total radial force $F_{s}$ is smaller than the reference value $F_{\text {ref }}$, and that $\Delta F$ goes beyond the upper bound $\Delta F_{\min }$, phase $\mathrm{A}$ is magnetized until $\Delta F \leq-\Delta F_{\min }$ when phase A switches into freewheeling. If $\Delta F$ keeps decreasing to $-\Delta F_{\max }$, the phase A switches turn off to prevent the overall radial force increasing further. By demagnetizing phase $\mathrm{A}$, the total radial force begins to decrease and phase $\mathrm{A}$ switches to freewheeling as soon as $\Delta F$ $\geq-\Delta F_{\text {min }}$. Finally, phase $\mathrm{A}$ is magnetized once $\Delta F$ exceeds the inner limitation $\Delta F_{\min }$.

\section{Coupling between the Torque and Radial Force}

According to Fig. 2, the overall torque reference is required to implement the optimal torque control (TMC). On the other hand, DFC demands the reference value of the total radial force that should be generated to decrease vibration. However, as only one reference signal is provided by the speed controller of the machine, a relationship between reference torque and reference radial force is necessary. In this paper, a static characteristics is obtained that allows to obtain the equivalent mean radial force value based on the equivalent mean torque value.

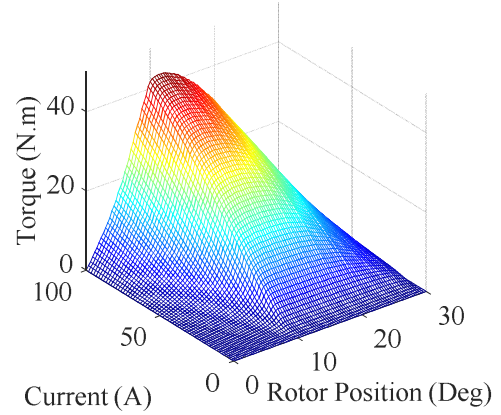

Fig. 7. Torque profile.

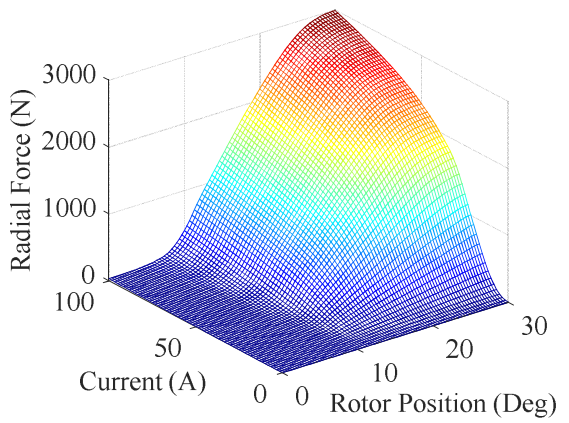

Fig. 8. Radial force profile.

It is well-known that the torque and radial force profiles for the SRM present a highly nonlinear behavior which is related to the phase current and rotor position (as shown in Fig. 7 and Fig. 8). Based on these profiles, the equivalent mean values of 
both torque and radial force during a half electrical period can be calculated, for each current, with the following expressions:

$$
\begin{aligned}
& T_{m}=\left.\frac{1}{\pi} \int_{0}^{\pi} T(I, \theta) d \theta\right|_{I=\text { const }} \\
& F_{m}=\left.\frac{1}{\pi} \int_{0}^{\pi} F(I, \theta) d \theta\right|_{I=\text { const }}
\end{aligned}
$$

Therefore, the relationship between the mean torque and radial force is obtained as illustrated in Fig. 9. Based on this static characteristics, the reference torque and reference radial force are estimated simultaneously for different constant currents.

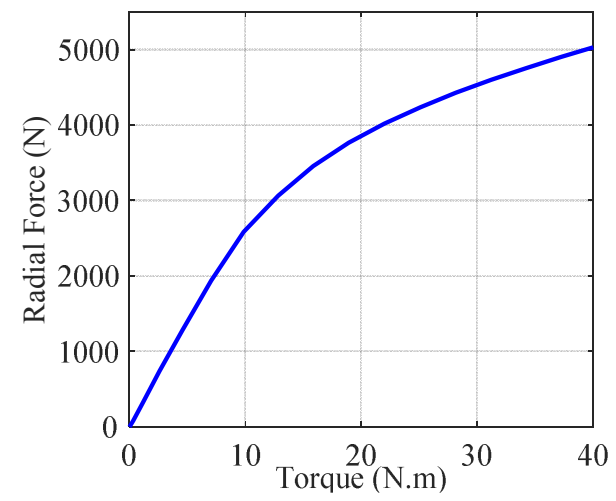

Fig. 9. Static characteristics between the overall torque and the total radial force.

\section{Reference Current Adapter}

The purpose of a reference current adapter is to manage the tradeoff between two control objectives, torque ripple minimization and vibration reduction, by updating the current reference used for current control. The value of the current reference is constantly adapted based on the variations of the torque and radial forces within an electrical period, noted $\sigma_{T}$ and $\sigma_{F}$ respectively. These values are calculated using the following expressions:

$$
\begin{gathered}
\sigma_{T}=\sqrt{\int_{0}^{T_{s}}\left(T(t)-T_{a v g}\right)^{2} d t} /\left(T_{a v g} T_{c}\right) \\
\sigma_{F}=\sqrt{\int_{0}^{T_{s}}\left(F(t)-F_{a v g}\right)^{2} d t} /\left(F_{a v g} T_{c}\right)
\end{gathered}
$$

where, $T(t), F(t)$ are the transient total torque and radial force, respectively; $T_{\text {avg }}, F_{\text {avg }}$ are the mean values of the total torque and radial force during one electrical period, respectively; $T_{c}$ is the cycle time of one electrical period.

The structure of the reference current adapter is illustrated in Fig. 10. The $I_{r e f}[k]$ is the output of the reference current adapter for temporary time $k$. Firstly, at each sampling instant,
$\sigma_{T}$ and $\sigma_{F}$ are determined and compared to constants $\varepsilon_{T}$ and $\varepsilon_{F}$ in order to compute the intermediate current reference $I_{n e w}[k]$ as follows:

$$
\begin{aligned}
& \begin{cases}I_{\text {new }}[k]=I_{\text {new }}[k-1]+\Delta I, & \text { when } \sigma_{F}>\varepsilon_{F} \\
I_{\text {new }}[k]=I_{\text {new }}[k-1], & \text { when } \sigma_{F} \leq \varepsilon_{F}\end{cases} \\
& \left\{\begin{array}{l}
I_{\text {new }}[k]=I_{\text {new }}[k-1]-\Delta I, \text { when } \sigma_{T}>\varepsilon_{T} \\
I_{\text {new }}[k]=I_{\text {new }}[k-1], \quad \text { when } \sigma_{T} \leq \varepsilon_{T}
\end{array}\right.
\end{aligned}
$$

where, $I_{\text {new }}[k]$ and $I_{\text {new }}[k-1]$ are the intermediate current reference values at time $k$ and $k-1$, in which the $I_{\text {new }}[k-1]=$ $I_{\text {ref }}[\mathrm{k}-1]$, the $I_{\text {ref }}[\mathrm{k}-1]$ is the value of the reference current adapter output for time $k-1 ; \varepsilon_{F}$ and $\varepsilon_{T}$ are upper limits for the variations of radial force and torque. These upper bounds are chosen by the user to weight the two control objectives. $\Delta I$ is a constant value. In this paper, $\varepsilon_{F}=0.45, \varepsilon_{T}=0.25, \Delta I=1$, where the values of $\varepsilon_{F}$ and $\varepsilon_{T}$ are the maximum value obtained from DFC and TMC, respectively.

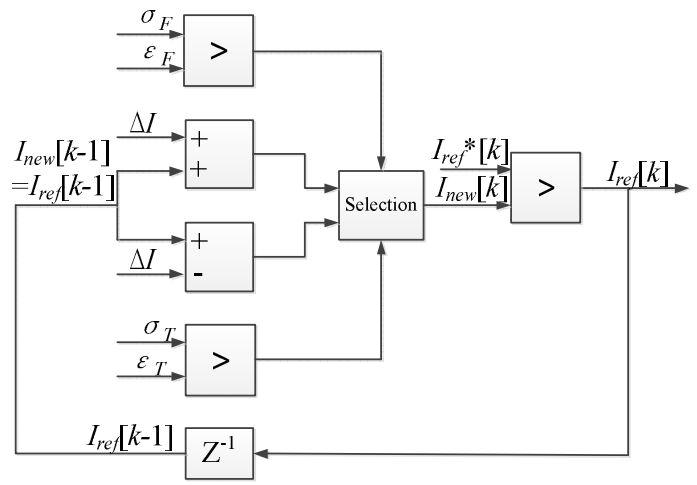

Fig. 10. Structure of the proposed reference current adapter.

It should be noted that the condition from (6) is checked only if the radial force variation does not exceed the upper limit $\varepsilon_{\mathrm{F}}$. If both variations of torque and radial force are inside their allowed range, the intermediate current reference $I_{n e w}[k]$ is compared with the current reference signal $\left.I_{r e f} * k\right]$. The reference current $\left.I_{r e f} * k\right]$ is obtained from the optimized lookup table to ensure the speed-up of the machine so that the the machine speed is increased faster than by using directly the value $I_{n e w}[k]$. Finally, the output of the reference current adapter is equal to the maximum between $I_{r e f}{ }^{*}[k]$ and $I_{n e w}[k]$.

The block diagram of the closed-loop SRM system combining the TMC, DFC and the auto-tuning reference current adapter, is illustrated in Fig. 11. The torque reference $T_{r e f}$ is computed by the speed controller and used first to select the optimal control parameters $I_{r e f}{ }^{*}, \psi$ and $\theta_{p}$ from the look-up table and, secondly, to determine the reference radial force based on the static radial force-torque characteristics. Then, the reference current $I_{r e f}{ }^{*}$ generated by the look-up table is compared to the one computed by the reference current adapter to obtain a new current reference $I_{\text {ref. }}$ Since the reference current adapter produces a new current reference $I_{\text {ref }}$, the reference torque $T_{r e f}$ will be temporarily quite different from 


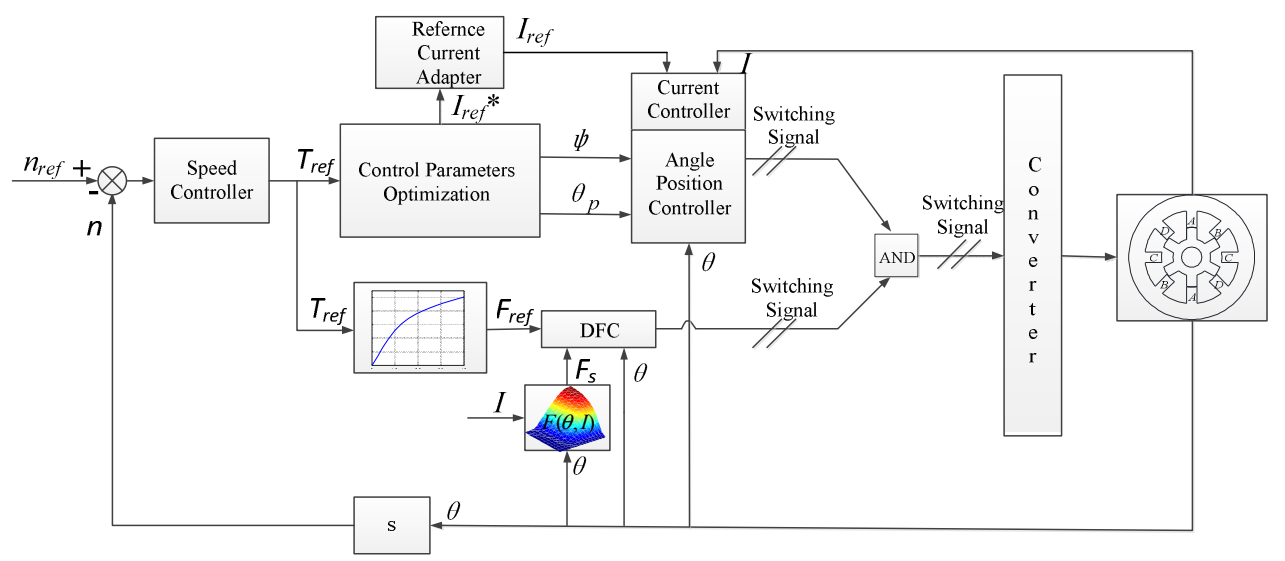

Fig. 11. Block diagram of the proposed method.

the desired one in the TMC. Finally, the switching signals from the current controller, angle position controller and DFC are combined together with a logic AND, then sent to the converter to the control the switches.

\section{SIMULATION RESULTS}

To verify the ability of the proposed control method to reduce vibration, simulations are carried out in MatlabSimulink. A vibration criterion is adopted to evaluate the performance of the control method in terms of vibration reduction based on the fact that the total energy $W$ gives a quantity related to the vibration behavior of all spectrum (all audible frequencies). The criteria is defined by the corresponding total energy $W$ deduced from the energy spectral density as follows:

$$
W=\int_{0}^{f_{\max }} a(f) a^{*}(f) d f
$$

where, $a(f)$ is the value of the acceleration FFT at the frequency $f ; a^{*}(f)$ is the complex conjugate of $a(f)$.

The vibration acceleration and the total torque obtained by applying TMC and proposed control strategies are compared in Fig. 12. According to simulation results, at a speed of $600 \mathrm{rpm}$ and a load torque of $3 \mathrm{~N} . \mathrm{m}$, the acceleration vibration is reduced without deteriorating the torque ripple and the total vibration energy is improved by $57.7 \%$.

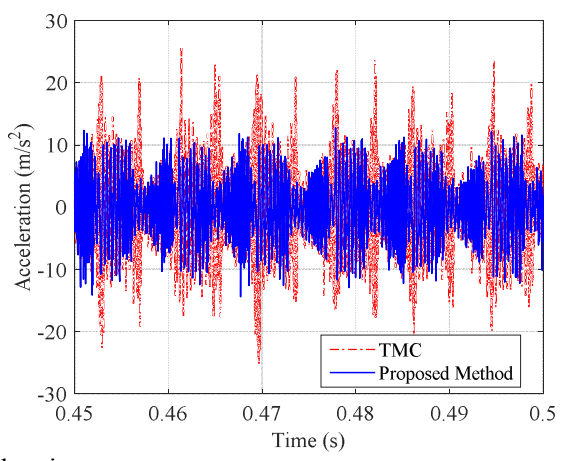

(a)Acceleration

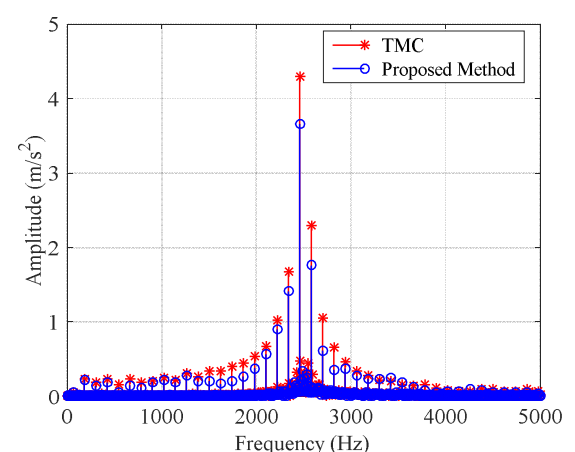

(b)Spectrum of acceleration

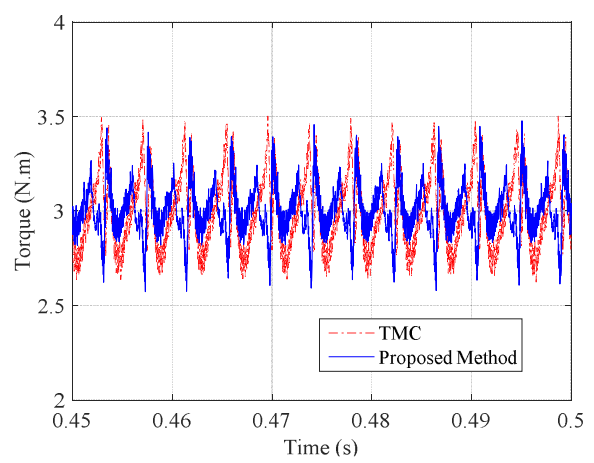

(c) Total torque

Fig. 12. Simualtion results at $n=600 \mathrm{rpm}$ and $T_{L}=3 \mathrm{~N} \cdot \mathrm{m}$, obtained using TMC (dash-dotted curve in (a) (c)) and proposed method (solid curve in (a) (c)).

To verify the effectiveness of the proposed control method, different torque loads and speeds are tested in simulation and the results are shown in TABLE II and TABLE III. It should be noted that all these results are obtained when the machine reaches the requested reference speed. According to TABLE II, it can be concluded that the proposed method captures the advantages of both control approaches (TMC, DFC) and vibration reduction is achieved while keeping the torque ripple in an admissible range. For the considered $8 / 6$ poles SRM, the total energy of the acceleration is reduced up to $75 \%$ at low speed and low load torque (at a speed of $300 \mathrm{rpm}$ and a load torque of $3 \mathrm{~N} . \mathrm{m}$ ), compared to TMC approach. Meanwhile, the torque ripple (the torque ripple definition is $\gamma=\left(T_{\max }-T_{\min }\right) / T_{\text {avg }}$, with $T_{\max }$ 
and $T_{\min }$ the maximum and minimum torque in one electrical period, respectively) obtained using the proposed method is limited to 0.8 for the considered operating points. Moreover, at high speed, the torque ripple at some operating points is even improved (the maximum improvement is at a speed of $1200 \mathrm{rpm}$ and a load torque of 12 N.m).

TABLE II. TOTAL ENERGY OF ACCELERATION FOR DIFFERENT OPERATING POINTS

\begin{tabular}{|l|c|c|c|}
\hline & TMC & $\begin{array}{c}\text { Proposed } \\
\text { Method }\end{array}$ & $\begin{array}{c}\text { Vibration } \\
\text { Improvement }\end{array}$ \\
\hline$n=300 \mathrm{rpm}, T_{L}=3 \mathrm{~N} . \mathrm{m}$ & 537 & 134 & $75 \%$ \\
\hline$n=300 \mathrm{rpm}, T_{L}=6 \mathrm{~N} . \mathrm{m}$ & 1066 & 670 & $37.1 \%$ \\
\hline$n=300 \mathrm{rpm}, T_{L}=9 \mathrm{~N} . \mathrm{m}$ & 1190 & 1099 & $7.6 \%$ \\
\hline$n=300 \mathrm{rpm}, T_{L}=12 \mathrm{~N} . \mathrm{m}$ & 967 & 893 & $7.7 \%$ \\
\hline$n=600 \mathrm{rpm}, T_{L}=3 \mathrm{~N} . \mathrm{m}$ & 874 & 370 & $57.7 \%$ \\
\hline$n=600 \mathrm{rpm}, T_{L}=6 \mathrm{~N} . \mathrm{m}$ & 808 & 744 & $7.9 \%$ \\
\hline$n=600 \mathrm{rpm}, T_{L}=9 \mathrm{~N} . \mathrm{m}$ & 847 & 510 & $39.8 \%$ \\
\hline$n=600 \mathrm{rpm}, T_{L}=12 \mathrm{~N} . \mathrm{m}$ & 773 & 331 & $57.2 \%$ \\
\hline$n=1200 \mathrm{rpm}, T_{L}=3 \mathrm{~N} . \mathrm{m}$ & 1022 & 315 & $69.2 \%$ \\
\hline$n=1200 \mathrm{rpm}, T_{L}=6 \mathrm{~N} . \mathrm{m}$ & 1795 & 870 & $51.5 \%$ \\
\hline$n=1200 \mathrm{rpm}, T_{L}=9 \mathrm{~N} . \mathrm{m}$ & 2345 & 848 & $63.8 \%$ \\
\hline$n=1200 \mathrm{rpm}, T_{L}=12 \mathrm{~N} . \mathrm{m}$ & 3197 & 2090 & $34.6 \%$ \\
\hline
\end{tabular}

TABLE III. TORQUE RIPPLE FOR DIFFERENT OPERATING POINTS

\begin{tabular}{|l|c|c|c|}
\hline & TMC & $\begin{array}{c}\text { Proposed } \\
\text { Method }\end{array}$ & $\begin{array}{c}\text { Torque ripple } \\
\text { Difference }\end{array}$ \\
\hline$n=300 \mathrm{rpm}, T_{L}=3 \mathrm{~N} . \mathrm{m}$ & 0.278 & 0.523 & +0.245 \\
\hline$n=300 \mathrm{rpm}, T_{L}=6 \mathrm{~N} . \mathrm{m}$ & 0.243 & 0.243 & 0 \\
\hline$n=300 \mathrm{rpm}, T_{L}=9 \mathrm{~N} . \mathrm{m}$ & 0.194 & 0.215 & +0.021 \\
\hline$n=300 \mathrm{rpm}, T_{L}=12 \mathrm{~N} . \mathrm{m}$ & 0.167 & 0.291 & +0.124 \\
\hline$n=600 \mathrm{rpm}, T_{L}=3 \mathrm{~N} . \mathrm{m}$ & 0.295 & 0.291 & -0.004 \\
\hline$n=600 \mathrm{rpm}, T_{L}=6 \mathrm{~N} . \mathrm{m}$ & 0.248 & 0.234 & -0.014 \\
\hline$n=600 \mathrm{rpm}, T_{L}=9 \mathrm{~N} . \mathrm{m}$ & 0.229 & 0.311 & +0.082 \\
\hline$n=600 \mathrm{rpm}, T_{L}=12 \mathrm{~N} . \mathrm{m}$ & 0.201 & 0.503 & +0.302 \\
\hline$n=1200 \mathrm{rpm}, T_{L}=3 \mathrm{~N} . \mathrm{m}$ & 0.533 & 0.526 & -0.007 \\
\hline$n=1200 \mathrm{rpm}, T_{L}=6 \mathrm{~N} . \mathrm{m}$ & 0.769 & 0.794 & +0.025 \\
\hline$n=1200 \mathrm{rpm}, T_{L}=9 \mathrm{~N} . \mathrm{m}$ & 0.761 & 0.749 & -0.012 \\
\hline$n=1200 \mathrm{rpm}, T_{L}=12 \mathrm{~N} . \mathrm{m}$ & 0.736 & 0.679 & -0.057 \\
\hline
\end{tabular}

\section{CONCLUSION}

In this paper, a control method regarding the torque ripple and vibration problem of the SRM is proposed. At first, an off-line optimal torque ripple control is introduced, which consists in optimizing the reference current $I_{\text {ref }}{ }^{*}$, turn on angle $\psi$ and conduction angle $\theta_{p}$ in order to minimize the torque ripple. Then, DFC method is presented as a solution for vibration reduction based on the limitation of the variation of the overall radial force. Moreover, the relationship between the equivalent radial force and torque is obtained which allows to combine DFC with TMC strategy. To handle the compromise between torque ripple minimization and vibration reduction, a reference current adapter is proposed. Furthermore, a criterion is put forward to assess the torque and radial force variation in order to obtain an auto-tuning current reference. Finally, the simulation results of the proposed control method are compared with TMC, showing that the vibration energy can be reduced up to $75 \%$ without further penalizing the torque ripple, proving the potential of the proposed method. The experimental validation is a work in progress.

\section{REFERENCES}

[1] D. E. Cameron, J. H. Lang, S. D. Umans, "The origin and reduction of acoustic noise in doubly salient variable-reluctance motors," IEEE Trans. Ind. Appl., vol. 28, no. 6, pp. 1250-1255, Nov/Dec 1992.

[2] M. Besbes, C. Picod, F. Camus, and M. Gabis, "Influence of stator geometry upon vibratory behavior and electromagnetic performances of switched reluctance motors," IET Electro. Power. App., vol. 145, no. 5, pp. 462-468, Sep 1998.

[3] K. Nakata, K. Hiramoto, M. Sanada, S. Morimoto and Y. Takeda, "Noise reduction for switched reluctance motor with a hole," in Proc. PCC-Osaka 2002. pp. 971-976.

[4] J. P. Hong, K. H. Ha, J. Lee, "Stator pole and yoke design for vibration reduction of switched reluctance motor," IEEE Trans. Magn., vol. 38, no. 2, pp. 929-932, Mar 2002.

[5] B. Fahimi, G. Suresh, K. M. Rahman, and M. Ehsani, "Mitigation of acoustic noise and vibration in switched reluctance motor drive using neural network based current profiling," in Conf. Rec. IEEE-IAS Annu. Meeting, vol. 1, 1998, pp. 715-722.

[6] C. Y. Wu, C. Pollock, "Analysis and reduction of vibration and acoustic noise in the switched reluctance drive," IEEE Trans Ind. Appl., vol. 31, no. 1, pp. 91-98, Jan/Feb 1995.

[7] C. Pollock, C. Y. Wu, "Acoustic noise cancellation techniques for switched reluctance drives," IEEE Trans. Ind. Appl., vol. 33, no. 2, pp. 477-484, Mar/Apr 1997.

[8] T. Boukhobza, M. Gabsi, B. Grioni, "Random variation of control angles, reduction of SRM vibrations," in Proc. IEMDC 2001, pp. 640-643.

[9] F. Blaabjerg, J. K. Pedersen, "Digital implemented random modulation strategies for ac and switched reluctance drives," in Proc. IECON'93, 1993, pp. 676-682.

[10] B. J. Kang, C. M. Liaw, "Random hysteresis PWM inverter with robust spectrum shaping," IEEE Trans. Aerosp. Electron. Syst., vol. 37, no. 2, pp. 619-629, Apr. 2001.

[11] J. W. Ahn, S. J. Park, D. H. Lee, "Hybrid excitation of SRM for reduction of vibration and acoustic noise," IEEE Trans. Ind. Electron., vol. 51, no. 2, pp. 374-380, Apr 2004.

[12] X. Ojeda, M. Gabsi, M. Lecrivain, X. Mininger, "Noise reduction using piezoelectric active control on high speeds switched reluctance drives," Conf. Rec. IEEE-IAS Annu. Meeting, 2007, pp. 2204-2209.

[13] X. Mininger, E. Lefeuvre, M. Gabsi, C. Richard and D. Guyomar, "Semiactive and active piezoelectric vibration controls for switched reluctance machine," IEEE Trans. Energy. Convers., vol. 23, no. 1, pp. 78-85, Mar 2008.

[14] X. Ojeda, X. Mininger, M. Gabsi, C. Kulcsar, H. F. Raynaud, and M. Lecrivain, "Design of controllers: Vibration damping of switched reluctance machine by piezoelectric actuators," ELECTROMOTION 2009, pp. 1-6.

[15] X. Ojeda, X. Mininger, M. Gabsi, and M. Lecrivain, "Noise cancellation of $6 / 4$ switched reluctance machine by piezoelectric actuators: Optimal design and placement using genetic algorithm," PEMD 2008, pp. 611-615.

[16] A. Hofmann, A. Al-Dajani, M. Bösing, and R. W. De Doncker, "Direct instantaneous force control: A method to eliminate mode-0borne noise in switched reluctance machines," IEMDC 2013, pp. 1009-1016.

[17] M. Takiguchi, H. Sugimoto, N. Kurihara, A. Chiba, "Acoustic noise and vibration reduction of SRM by elimination of third harmonic component in sum of radial forces," IEEE Trans. Energy. Convers., vol. 30, no. 3, pp. 883-891, Sept 2015.

[18] N. Kurihara, J. Bayless, A. Chiba, "Noise and vibration reduction of switched reluctance motor with novel simplified current waveform to reduce force sum variation," IEMDC 2015, pp. 1794-1800

[19] A. Kolli, G. Krebs, X. Mininger, and C. Marchand, "Impact of command parameters on efficiency, torque ripple and vibrations for Switched Reluctance motor," ICEM 2012, pp. 2975-2980.

[20] H. Qi, T. Zhang, Z. Li, Y. Wei, "SRM Torque Ripple Minimization Based on Direct Instantaneous Torque Control," Transactions of china electrotechnical society, vol. 22, no. 7, pp. 136-140, Jul 2007. 